\title{
Racial and Ethnic Differences in BRCA1/2 and Multigene Panel Testing Among Young Breast Cancer Patients
}

\author{
T Jones $^{1}$ (D) $\cdot$ MS Trivedi $^{2} \cdot$ X Jiang $^{2} \cdot$ T Silverman $^{2} \cdot$ M Underhill $^{3} \cdot$ WK Chung $^{2} \cdot$ R Kukafka $^{2} \cdot \mathrm{KD} \mathrm{Crew}^{2}$ \\ Published online: 4 December 2019 \\ (C) The Author(s) 2019
}

\begin{abstract}
Genetic testing for hereditary breast and ovarian cancer (HBOC) is recommended for breast cancer patients diagnosed at age $\leq 50$ years. Our objective was to examine racial/ethnic differences in genetic testing frequency and results among diverse breast cancer patients. A retrospective cohort study among women diagnosed with breast cancer at age $\leq 50$ years from January 2007 to December 2017 at Columbia University in New York, NY. Among 1503 diverse young breast cancer patients, nearly half (46.2\%) completed HBOC genetic testing. Genetic testing completion was associated with younger age, family history of breast cancer, and earlier stage, but not race/ethnicity or health insurance status. Blacks had the highest frequency of pathogenic/likely pathogenic (P/LP) variants (18.6\%), and Hispanics and Asians had the most variants of uncertain significance (VUS), $19.0 \%$ and $21.9 \%$, respectively. The percentage of women undergoing genetic testing increased over time from $15.3 \%$ in 2007 to a peak of $72.8 \%$ in 2015. Over the same time period, there was a significant increase in P/LP and VUS results. Due to uncertainty about the clinical implications of P/LP variants in moderate penetrance genes and VUSs, our findings underscore the need for targeted genetic counseling education, particularly among young minority breast cancer patients.
\end{abstract}

Keywords $B R C A 1 / 2$ genetic testing $\cdot$ Multigene panel testing $\cdot$ Young breast cancer patients $\cdot$ Racial/ethnic minorities

\section{Introduction}

Germline genetic testing is the recommended standard of care for young breast cancer patients diagnosed at age $\leq 50$ years due to an increased risk of hereditary breast and ovarian cancer (HBOC) syndrome [1]. BRCA1 and BRCA2 (BRCA1/2) gene mutations confer breast and ovarian cancers risks from $35 \%$ to $65 \%$ and $5 \%$ to $50 \%$, respectively [2]. In addition, numerous other high-penetrance genes such as $C D H 1$, PTEN, STK11, TP53, and PALB2 are associated with hereditary breast cancer, making multigene panel testing for hereditary cancer risk of critical importance in young breast cancer

T Jones

Jonest@health.fau.edu

1 Florida Atlantic University, Christine E. Lynn College of Nursing, Boca Raton, FL 33431, USA

2 Columbia University Irving Medical Center, New York, NY 10032, USA

3 Dana Farber Cancer Institute, Boston, MA 02215, USA patients [3]. Although multigene panel testing offers more comprehensive cancer risk assessment, there is greater uncertainty in clinical decision-making due to increased likelihood of variants of uncertain significance (VUS), particularly among racial/ethnic minorities who have been found to have more frequent VUS results compared to non-Hispanic Whites [4]. Once a pathogenic variant is identified, interventions available include risk-reducing contralateral prophylactic mastectomy, bilateral salpino-oophorectomy (BSO), or intensive screening with annual mammography and breast magnetic resonance imaging (MRI) for early detection [2, 5]. In addition, individuals with a $B R C A 1 / 2$ gene mutation with HER2-negative metastatic breast cancer may benefit from treatment with a PARP inhibitor. Young breast cancer patients diagnosed at 50 years or younger represent approximately $19 \%$ of new breast cancer cases in the USA [6]. In comparison to postmenopausal women, younger women are more likely to develop aggressive subtypes of breast cancer, have a worse prognosis with increased risk of recurrence, and have higher overall mortality [7]. Young breast cancer patients are also more likely to be diagnosed with triple-negative breast cancer (TNBC), which is associated with a higher frequency of 
BRCA1 mutations [8]. Previous investigations among young breast cancer patients have found an underutilization of germline genetic testing $[9,10]$, but have been limited by small sample size, lack of diversity, and examination of BRCA1/2 genes only. Larger studies of young breast cancer patients are needed to provide a comprehensive understanding of multigene panel testing. To address this gap, we examined frequency and predictors of $B R C A 1 / 2$ and multigene panel testing and assessed racial/ethnic differences in genetic testing frequency and results (pathogenic/likely pathogenic [P/LP], VUS, negative) among diverse women with early-onset breast cancer.

\section{Methods}

We conducted a retrospective cohort study among women diagnosed with early-onset breast cancer (age $\leq 50$ years) at Columbia University Irving Medical Center (CUIMC) in New York, NY from 2007 to 2017. Eligible participants included women diagnosed with invasive breast cancer or ductal carcinoma in situ (DCIS) at age $\leq 50$ years between January 2007 and December 2017 with electronic health record (EHR) data available at CUIMC. Participants were ascertained via the New York-Presbyterian Hospital (NYPH) Tumor Registry at CUIMC. This study was approved by the Institutional Review Board at CUIMC and Florida Atlantic University. All participants met current National Comprehensive Cancer Network $(\mathrm{NCCN})$ criteria for further cancer risk assessment evaluation for HBOC risk [1].

Patient demographics including age at diagnosis, race/ ethnicity (non-Hispanic White, non-Hispanic Black, Hispanic, Asian, and other/unknown), marital status (married and unmarried), primary health insurance status (Medicare, Medicaid, private insurance, and other/uninsured), any structured family history of breast cancer (yes/no), breast tumor characteristics (i.e., stage at diagnosis), and year of diagnosis (prior to 2008, 2008-2010, 2011-2013, and after 2013) were collected through data extraction from the electronic health record (EHR) and New York-Presbyterian Hospital (NYPH) Tumor Registry.

Our primary outcome was the completion of germline genetic testing, dichotomized as genetic testing (yes/no) and classified by either $B R C A 1 / 2$ genetic testing only or multigene panel testing. Manual chart review was completed to extract genetic test results from the EHR, defined as positive (pathogenic/likely pathogenic [P/LP] variant), negative (no pathogenic variant), or variant of uncertain significance (VUS) at the time the original report was issued. We also extracted data on multigene panel testing (yes/no), the number of genes tested, and the frequency of $\mathrm{P} / \mathrm{LP}$ variants or VUS for each gene.

\section{Statistical Analysis}

We used descriptive statistics to characterize the study population, including demographic and clinical characteristics, and genetic testing frequency and results. Chi-squared test, or Fisher's exact test for cell ranges below 5, was utilized to assess differences in study population characteristics among women who had genetic testing performed and those who did not. Two-sample $t$ test was used to compare frequency distributions of continuous variables between those who completed and those who did not complete genetic testing, and the Satterthwaite approximation was used when variances were unequal. Univariate analysis was conducted to give an unadjusted estimate of the risk associated with each variable on frequency of genetic testing. We performed multivariate logistic regression analyses to examine the association between race/ethnicity and frequency of genetic testing, while controlling for covariates. Variables were included in the multivariate model if they were significant $(p<0.20)$ in the univariate model and if they changed the parameter estimate by at least $10 \%$. A secondary analysis of participants who completed genetic testing was also conducted using the same methodology. The subset of participants who completed genetic testing was stratified by genetic test results ( $\mathrm{P} / \mathrm{LP}$ variant, VUS, negative). To test for changes in genetic testing over time, we used the Cochran-Armitage test for trend. All statistical analysis was conducted using SAS version 9.4 (SAS Institute, Cary, $\mathrm{NC}$ ), and a $p$ value $<0.05$ was considered statistically significant.

\section{Results}

A total of 1621 patients with breast cancer diagnosed at age 50 years or younger between 2007 and 2017 at CUIMC were identified, and 118 patients were excluded from the study, including 94 (5.8\%) with lobular carcinoma in situ, 19 (1.2\%) with no available EHR data at CUIMC, and $5(0.3 \%)$ males. Among 1503 evaluable patients, mean age of 42.7 years (SD, 5.8), 42.4\% were non-Hispanic White, $13.3 \%$ non-Hispanic Black, 25.5\% Hispanic, 9.9\% Asian, and 8.9\% other or unknown race/ethnicity. The majority $(60.5 \%)$ of patients had private insurance, $22.8 \%$ had Medicaid, $7.2 \%$ had Medicare (either due to disability or existing co-morbidities), and $9.4 \%$ had other insurance or were uninsured. Nearly half (46.2\%) completed genetic testing (Table 1). Participants who completed genetic testing were more likely to be younger, be married, have a family history of breast cancer, have stage 1 breast cancer, and be diagnosed after 2013. There were no significant differences in the completion of genetic testing based upon race/ethnicity or primary health insurance status. Among 683 women who completed genetic testing (Table 2), $12.7 \%$ had P/LP variants and $13.9 \%$ had VUSs. Among $87 \mathrm{P} /$ 
LP variants detected, $46.0 \%$ were in $B R C A 1,27.6 \% B R C A 2$, $6.9 \%$ CHEK2, $4.6 \%$ ATM, and $14.9 \%$ in nine other genes. Among 130 VUSs detected, $11.5 \%$ were in BRCA1, $10.8 \%$ BRCA2, $10.0 \%$ ATM, $6.9 \%$ CHEK2, and $60.8 \%$ in 32 other genes. Non-Hispanic Blacks and Whites had the highest frequency of P/LP variants (18.2\% and $16.3 \%$, respectively), whereas Asians and Hispanics had the highest frequency of VUSs (21.9\% and $19.0 \%$, respectively). The percentage of women undergoing $\mathrm{HBOC}$ genetic testing increased over time (Cochran-Armitage test for trend, $p<.001$ ), from $15.3 \%$ in 2007 to a peak of $72.8 \%$ in 2015 (Fig. 1). Over the same time period, there was a significant increase in P/LP and VUS results.

Table 1 Baseline characteristics stratified by genetic testing completion and multivariable regression model of the association between sociodemographic and clinical factors and genetic testing completion
In multivariable analysis (Table 1), women who were older at breast cancer diagnosis were less likely to have genetic testing (odds ratio [OR], 0.93; 95\% confidence interval [CI], $0.91-0.95 ; p<0.001)$. The odds of a young woman completing genetic testing increased nearly 3 -fold if she had a family history of breast cancer (OR, 2.84; 95\% CI, 2.09-3.86; $p<$ 0.001). Compared to patients with stage 1 breast cancer, those with stage 0 or stage 4 disease at diagnosis were less likely to complete genetic testing (OR, $0.62 ; 95 \% \mathrm{CI}, 0.43-0.88 ; p=$ 0.007 and OR, 0.38 ; 95\% CI, $0.23-0.65 ; p<0.001$, respectively). Compared to those diagnosed before 2008, patients diagnosed after 2013 were over 10 times more likely to have genetic testing (OR, 10.29; 95\% CI, 7.09-14.94; $p<0.001$ ).

among young breast cancer patients diagnosed at Columbia University Irving Medical Center, New York, NY (2007-2017)

\begin{tabular}{|c|c|c|c|c|c|c|}
\hline Characteristic & $\begin{array}{l}\text { No genetic testing } \\
N=808(53.8 \%)\end{array}$ & $\begin{array}{l}\text { Genetic testing } \\
N=695(46.2 \%)\end{array}$ & $p$ value & Multi-variable*; odds ratio & $95 \%$ confidence interval & $p$ value \\
\hline Mean age at diagnosis, years (SD) & $43.6(5.5)$ & $41.7(6.0)$ & $<.001$ & 0.93 & $(0.91,0.95)$ & $<.001$ \\
\hline \multicolumn{7}{|l|}{ Race/ethnicity } \\
\hline Non-Hispanic White & $355(43.9)$ & $282(40.6)$ & \multirow[t]{5}{*}{0.242} & 1.00 & & \\
\hline Non-Hispanic Black & $110(13.6)$ & $90(12.9)$ & & 1.01 & $(0.66,1.48)$ & 0.969 \\
\hline Hispanic & 191 (23.6) & $192(27.6)$ & & 1.36 & $(0.98,1.89)$ & 0.068 \\
\hline Asian & $75(9.3)$ & $74(10.6)$ & & 0.89 & $(0.59,1.33)$ & 0.558 \\
\hline Other & $77(9.5)$ & $57(8.2)$ & & 1.02 & $(0.65,1.60)$ & 0.939 \\
\hline \multicolumn{7}{|l|}{ Marital status } \\
\hline Married & $326(40.3)$ & $304(43.7)$ & \multirow[t]{2}{*}{0.132} & 1.32 & \multirow[t]{2}{*}{$(1.03,1.71)$} & \multirow[t]{2}{*}{0.030} \\
\hline Unmarried & $482(59.7)$ & $391(56.3)$ & & 1.00 & & \\
\hline \multicolumn{7}{|l|}{ Insurance } \\
\hline Private & $483(59.8)$ & $427(61.4)$ & \multirow[t]{4}{*}{0.410} & 1.00 & & \\
\hline Medicare & $66(8.2)$ & $42(6.0)$ & & 1.25 & $(0.75,2.06)$ & 0.391 \\
\hline Medicaid & $180(22.3)$ & $163(23.5)$ & & 0.82 & $(0.59,1.12)$ & 0.210 \\
\hline Uninsured/other & $79(9.8)$ & $63(9.1)$ & & 0.78 & $(0.51,1.20)$ & 0.260 \\
\hline \multicolumn{7}{|l|}{ Stage } \\
\hline 0 & $139(17.2)$ & $95(13.7)$ & \multirow[t]{6}{*}{$<.001$} & 0.62 & \multirow[t]{2}{*}{$(0.43,0.88)$} & \multirow[t]{2}{*}{0.007} \\
\hline 1 & $219(27.1)$ & $262(37.7)$ & & 1.00 & & \\
\hline 2 & $194(24.0)$ & $220(31.7)$ & & 0.91 & $(0.67,1.23)$ & 0.538 \\
\hline 3 & $72(8.9)$ & $58(8.3)$ & & 0.84 & $(0.54,1.32)$ & 0.452 \\
\hline 4 & $55(6.8)$ & $36(5.2)$ & & 0.38 & $(0.23,0.65)$ & $<.001$ \\
\hline Unknown & $129(16.0)$ & $24(3.5)$ & & 0.37 & $(0.22,0.63)$ & $<.001$ \\
\hline \multicolumn{7}{|l|}{ Family history of breast cancer } \\
\hline Yes & $96(11.9)$ & $203(29.2)$ & \multirow[t]{2}{*}{$<.001$} & 2.84 & \multirow[t]{2}{*}{$(2.09,3.86)$} & \multirow[t]{2}{*}{$<.001$} \\
\hline No & $712(88.1)$ & $492(70.8)$ & & 1.00 & & \\
\hline \multicolumn{7}{|l|}{ Year of diagnosis } \\
\hline Prior to 2008 & $316(39.1)$ & $61(8.8)$ & \multirow[t]{4}{*}{$<.001$} & 1.00 & & \\
\hline 2008-2010 & $168(20.8)$ & $84(12.1)$ & & 2.78 & $(1.86,4.17)$ & 0.004 \\
\hline 2011-2013 & $148(18.3)$ & $221(31.8)$ & & 8.34 & $(5.73,12.13)$ & $<.001$ \\
\hline After 2013 & $176(21.8)$ & $329(47.3)$ & & 10.29 & $(7.09,14.94)$ & $<.001$ \\
\hline
\end{tabular}

Entries in italics indicate statisticially significant variables

*Multivariable logistic regression model was adjusted for age, insurance, stage of breast cancer, family history of breast cancer, and year of diagnosis 
Table 2 Patient characteristics by genetic test results among young women diagnosed with breast cancer at Columbia University Irving Medical Center, New York, NY (2007-2017)

\begin{tabular}{|c|c|c|c|c|c|}
\hline Characteristic & $\begin{array}{l}\text { Genetic test result: } \\
\text { Positive } \\
N(\%)^{1} \\
N=87(12.7 \%)\end{array}$ & $\begin{array}{l}\text { Genetic test result: VUS } \\
\mathrm{N}(\%)^{1} \\
N=95(13.9 \%)\end{array}$ & $\begin{array}{l}\text { Genetic test result: Negative } \\
N(\%)^{1} \\
N=501(73.4 \%)\end{array}$ & $\begin{array}{l}\text { Total } \\
N(\%)^{2} \\
N=683^{3}\end{array}$ & $p$ value \\
\hline \multicolumn{6}{|l|}{ Age at diagnosis (years) } \\
\hline Mean (SD) & $40.6(6.5)$ & $41.4(6.3)$ & $41.9(5.8)$ & $41.7(6.0)$ & 0.150 \\
\hline \multicolumn{6}{|l|}{ Race/ethnicity, $N(\%)$} \\
\hline Non-Hispanic White & $45(16.3)$ & $24(8.7)$ & $207(75.0)$ & $276(40.4)$ & \\
\hline Non-Hispanic Black & $16(18.2)$ & $12(13.6)$ & $60(68.2)$ & $88(12.9)$ & \\
\hline Hispanic & $15(7.9)$ & $36(19.0)$ & $138(73.0)$ & $189(27.7)$ & \\
\hline Asian & $6(8.2)$ & $16(21.9)$ & $51(69.9)$ & $73(10.7)$ & \\
\hline Other & $5(8.8)$ & $7(12.3)$ & $45(78.9)$ & $57(8.3)$ & 0.003 \\
\hline \multicolumn{6}{|l|}{ Marital status, $N(\%)$} \\
\hline Married & $34(11.4)$ & $33(11.1)$ & $231(77.5)$ & $298(43.6)$ & \\
\hline Unmarried & $53(13.8)$ & $62(16.1)$ & $270(70.1)$ & $385(56.4)$ & 0.091 \\
\hline \multicolumn{6}{|l|}{ Insurance, $N(\%)$} \\
\hline Private & $55(13.1)$ & $57(13.6)$ & $307(73.3)$ & $419(61.3)$ & \\
\hline Medicare & $3(7.1)$ & $3(7.1)$ & $36(85.7)$ & $42(6.1)$ & \\
\hline Medicaid & $21(13.0)$ & $19(11.8)$ & $121(75.2)$ & $161(23.6)$ & \\
\hline Uninsured/other & $8(13.1)$ & $16(26.2)$ & $37(60.7)$ & $61(8.9)$ & 0.037 \\
\hline \multicolumn{6}{|l|}{ Stage, $N(\%)$} \\
\hline 0 & $7(7.6)$ & $7(7.6)$ & $78(84.8)$ & $92(13.5)$ & \\
\hline 1 & $36(14.0)$ & $33(12.8)$ & $189(73.3)$ & $258(37.8)$ & \\
\hline 2 & $30(13.9)$ & $39(18.1)$ & $147(68.1)$ & $216(31.6)$ & \\
\hline 3 & $7(12.1)$ & $8(13.8)$ & $43(74.1)$ & $58(8.5)$ & \\
\hline 4 & $3(8.6)$ & $5(14.3)$ & $27(77.1)$ & $35(5.1)$ & \\
\hline Unknown & $4(16.7)$ & $3(12.5)$ & $17(70.8)$ & $24(3.5)$ & 0.342 \\
\hline \multicolumn{6}{|c|}{ Family history of breast cancer, $N(\%)$} \\
\hline Yes & $31(15.4)$ & $28(13.9)$ & $142(70.6)$ & $201(29.4)$ & \\
\hline No & $56(11.6)$ & $67(13.9)$ & $359(74.5)$ & $482(70.6)$ & 0.344 \\
\hline \multicolumn{6}{|c|}{ Year of diagnosis, $N(\%)$} \\
\hline Prior to 2008 & $6(9.8)$ & $5(8.2)$ & $50(82.0)$ & $61(8.9)$ & \\
\hline $2008-2010$ & $13(15.9)$ & $8(9.8)$ & $61(74.4)$ & $82(12.0)$ & \\
\hline 2011-2013 & $21(9.6)$ & $9(4.1)$ & $188(86.2)$ & $218(31.9)$ & \\
\hline After 2013 & $47(14.6)$ & $72(22.7)$ & $202(62.7)$ & $322(47.1)$ & $<.001$ \\
\hline
\end{tabular}

Entries in italics indicate statisticially significant variables

${ }^{1}$ Row percentages

2 Column percentages

${ }^{3}$ Excludes 12 patients- had genetic testing but no documentation of the results in their medical record

\section{Discussion}

We examined frequency and predictors of completion of BRCA1/2 and multigene panel testing and assessed racial/ ethnic differences in genetic testing frequency and results among breast cancer patients diagnosed at age $\leq 50$ years.
Nearly half of the young breast cancer patients completed genetic testing with no differences found in frequency based on race/ethnicity. In our multivariable analysis, we found that younger age at diagnosis, family history of breast cancer, stage of diagnosis, and year of diagnosis were important predictors of the completion of genetic testing. Similar to recent findings 
[11], we found that the percentage of young women diagnosed with breast cancer who completed germline genetic testing increased over time, with $73 \%$ of patients completing HBOC genetic testing in 2015.

Few studies in the USA have addressed germline genetic testing in young diverse breast cancer patients in an era of multigene panel testing. Two previous studies that examined the frequency of $B R C A 1 / 2$ genetic testing in young breast cancer patients diagnosed at age $\leq 45$ years found that $72.9 \%$ of their sample $[12,13]$ had genetic testing in one study [12], and $87 \%$ of the women reported testing 1-year post diagnosis in the second study [14]. Other previous studies of young women with breast cancer found lower frequency of BRCA1/2 genetic testing among young breast cancer patients ranging from $21 \%$ to $24 \%$ reporting that they completed testing, but these studies were based on self-report and limited to $B R C A 1 / 2$ genetic testing only $[9,15]$. Our results extend the current literature as we also examined completion of multigene panel testing among diverse young breast cancer patients.

Our findings are consistent with previous studies showing that women with a family history of breast cancer and those diagnosed in recent years were more likely to have genetic testing $[12,14]$. This suggests an increased awareness and improvement in access to cancer genetic testing based on national recommendations. However, it is important to consider factors that have impacted the increase in genetic testing over the years. In 2013, the Affordable Care Act (ACA) provided coverage for $B R C A 1 / 2$ genetic testing to guarantee zero out-of-pocket costs, which may have increased accessibility of genetic testing [16]. In a review exploring the impact of the "Angelina Jolie Effect," Gianmarco et al. reported an increase of referrals for genetic counseling with a nearly 3 -fold increase in BRCA1/2 genetic testing [17]. Additionally, in 2013 in the case of Association for Molecular Pathology v. Myriad Genetics, the US Supreme Court ruled unanimously that naturally occurring DNA was a product of nature and not patent eligible [18]. Rising public awareness about $B R C A 1 / 2$ genetic testing since 2013 has also led to an increase in receipt of genetic testing [19]. Recent recommendations from the American College of Medical Genetics and Genomics (ACMG) specify the standards for the interpretations of sequence variations, which possibly increased the frequency of VUS, as variant calling became more common [20].

In our study, we found that women with metastatic breast cancer were over $60 \%$ less likely to undergo genetic testing compared to women with stage I disease, which is consistent with the prior literature [21]. Recently, BRCA1/2 genetic test results have become increasingly relevant for systemic treatment decisions with the use of poly ADP-ribose polymerase

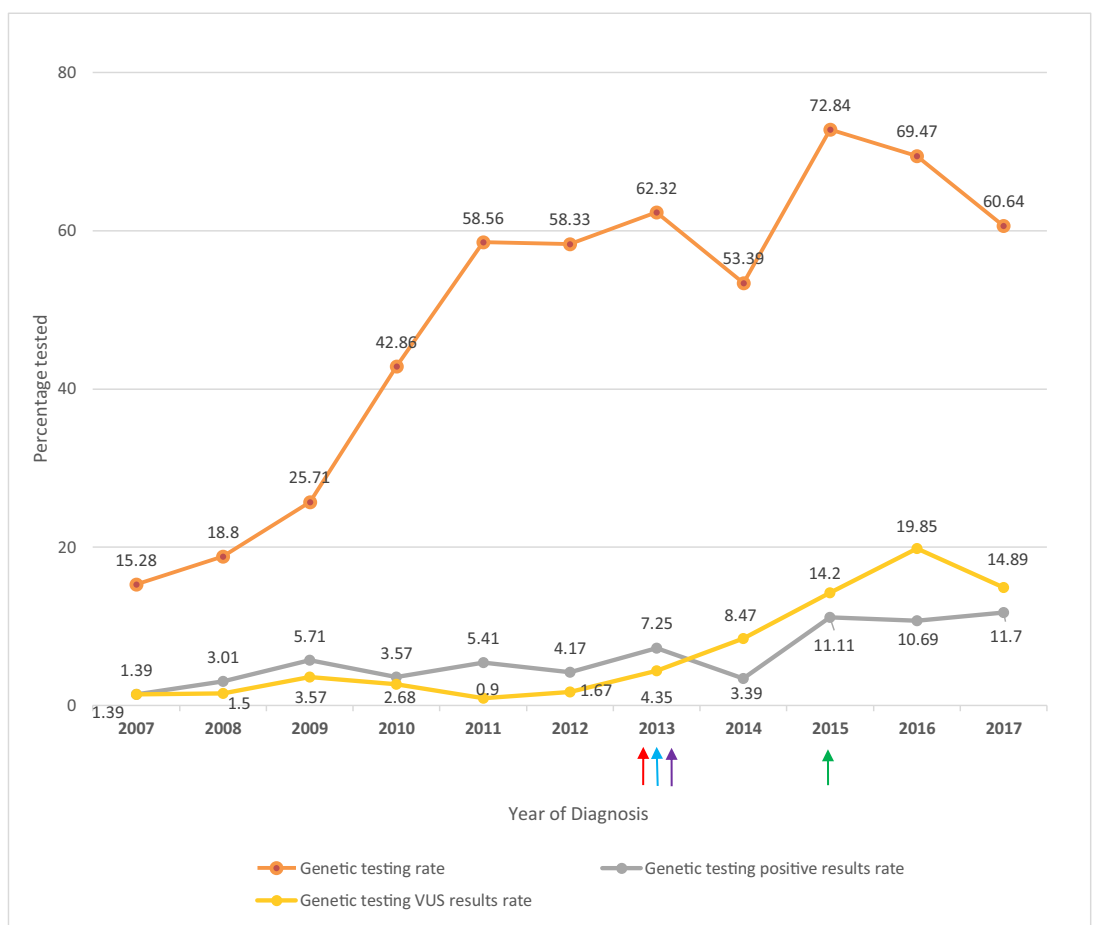

Fig. 1 Trends over time in germline genetic testing, positive and VUS results in a cohort of young women diagnosed with breast cancer $(N=$ 607) by year of diagnosis at Columbia University Irving Medical Center, New York, NY (2007-2017). Red arrow indicates when the Affordable Care Act clarified coverage for $B R C A 1 / 2$ genetic testing to guarantee zero out-of-pocket costs, 2013. Blue arrow indicates when actor Angelina
Jolie disclosed her BRCA genetic testing results, May 2013. Purple arrow indicates the US Supreme court vs. Myriad case, which increased the number of labs offering testing, 2013. Green arrow indicates the American College of Medical Genetics and Genomics (ACMG) Standards and guidelines for the interpretation of sequence variants, 2015 
(PARP) inhibitors for $B R C A 1 / 2$-associated metastatic breast cancer [22]. Furthermore, once a cancer-predisposing P/LP variant has been identified in patients with breast cancer, atrisk relatives can also receive genetic testing.

This study provides insights into P/LP variants in HBOC genes among young breast cancer patients. Furthermore, we observed racial/ethnic disparities in genetic testing results with the highest frequency of P/LP variants among young nonHispanic Black breast cancer patients followed by nonHispanic women of European ancestry. One possible explanation is that Black breast cancer patients with extensive family history and strong breast cancer risk factors elect to have genetic testing. Since the burden of breast cancer is particularly high among young Black women, with a mortality rate that is two times greater among young women of European ancestry [23], there is a need to engage more young Black breast cancer patients in genetic counseling education and the importance of having $\mathrm{HBOC}$ genetic testing performed. In addition, the frequency of VUSs was highest among Asians and Hispanics compared to the other racial/ethnic groups in our sample. These findings corroborate recent studies that have also reported higher frequencies of VUS among racial/ethnic minority breast cancer patients compared to women of European ancestry due to limited understanding of the normal spectrum of genetic variation in minority groups $[4,11]$. Since ethnic minority breast cancer patients may have lower health literacy, increased distress with VUS results, and confusion about the implications of VUSs, our findings underscore the need for targeted genetic counseling education among minority women [24]. However, the overwhelming majority of VUS will be reclassified as likely benign/benign over time with increasing data on allele frequencies across all ethnic groups, increasing data deposition to databases such as ClinVar, improved prediction algorithms, and functional studies [25].

Strengths of our study include a large sample size of women with early-onset breast cancer diagnosed over a long time period, a racially/ethnically diverse sample, and detailed clinical data from the EHR. Limitations include the retrospective cohort design and under-reporting of genetic testing, if counseling and testing occurred at an outside institution. Since this study was conducted at a single urban academic institution with access to genetic counseling services, our results may not be generalizable to other populations and should be confirmed in other geographic and clinical settings.

In summary, we did not observe a difference in HBOC genetic testing among young breast cancer patients based upon race/ethnicity; however, we observed a high frequency of pathogenic/likely pathogenic variants among non-Hispanic Black and non-Hispanic White women and there were more VUS results among minority women. Due to uncertainty about the clinical implications of P/LP variants in moderate penetrance genes and VUSs, our findings underscore the need for targeted genetic counseling education, particularly among young minority women [24].

Funding Information National Cancer Institute (R01 CA177995-01A1, R01CA177995-05S1, P30 CA013696-39), and National Center for Advancing Translational Sciences, National Institutes of Health (UL1 TR000040, U01HG008680)

Open Access This article is distributed under the terms of the Creative Commons Attribution 4.0 International License (http:// creativecommons.org/licenses/by/4.0/), which permits unrestricted use, distribution, and reproduction in any medium, provided you give appropriate credit to the original author(s) and the source, provide a link to the Creative Commons license, and indicate if changes were made.

\section{References}

1. National Comprehensive Cancer Network (NCCN). Genetic/ familial high-risk assessment: breast and ovarian 2018 [cited 2018; Version2.2019:[Available from: https://www.nccn.org/ professionals/physician_gls/pdf/genetics_screening.pdf.

2. Rebbeck TR, Friebel TM, Friedman E, Hamann U, Huo D, Kwong A, Olah E, Olopade OI, Solano AR, Teo SH, Thomassen M, Weitzel JN, Chan TL, Couch FJ, Goldgar DE, Kruse TA, Palmero EI, Park SK, Torres D, van Rensburg E, McGuffog L, Parsons MT, Leslie G, Aalfs CM, Abugattas J, Adlard J, Agata S, Aittomäki K, Andrews L, Andrulis IL, Arason A, Arnold N, Arun BK, Asseryanis E, Auerbach L, Azzollini J, Balmaña J, Barile M, Barkardottir RB, Barrowdale D, Benitez J, Berger A, Berger R, Blanco AM, Blazer KR, Blok MJ, Bonadona V, Bonanni B, Bradbury AR, Brewer C, Buecher B, Buys SS, Caldes T, Caliebe A, Caligo MA, Campbell I, Caputo SM, Chiquette J, Chung WK, Claes KBM, Collée JM, Cook J, Davidson R, de la Hoya M, de Leeneer K, de Pauw A, Delnatte C, Diez O, Ding YC, Ditsch N, Domchek SM, Dorfling CM, Velazquez C, Dworniczak B, Eason J, Easton DF, Eeles R, Ehrencrona H, Ejlertsen B, EMBRACE, Engel C, Engert S, Evans DG, Faivre L, Feliubadaló L, Ferrer SF, Foretova L, Fowler J, Frost D, Galvão HCR, Ganz PA, Garber J, Gauthier-Villars M, Gehrig A, GEMO Study Collaborators, Gerdes AM, Gesta P, Giannini G, Giraud S, Glendon G, Godwin AK, Greene MH, Gronwald J, Gutierrez-Barrera A, Hahnen E, Hauke J, HEBON, Henderson A, Hentschel J, Hogervorst FBL, Honisch $\mathrm{E}$, Imyanitov EN, Isaacs $\mathrm{C}$, Izatt L, Izquierdo A, Jakubowska A, James P, Janavicius R, Jensen UB, John EM, Vijai J, Kaczmarek K, Karlan BY, Kast K, Investigators K, Kim SW, Konstantopoulou I, Korach J, Laitman Y, Lasa A, Lasset C, Lázaro C, Lee A, Lee MH, Lester J, Lesueur F, Liljegren A, Lindor NM, Longy M, Loud JT, Lu KH, Lubinski J, Machackova E, Manoukian S, Mari V, Martínez-Bouzas C, Matrai Z, Mebirouk N, Meijers-Heijboer HEJ, Meindl A, Mensenkamp AR, Mickys U, Miller A, Montagna M, Moysich KB, Mulligan AM, Musinsky J, Neuhausen SL, Nevanlinna H, Ngeow J, Nguyen HP, Niederacher D, Nielsen HR, Nielsen FC, Nussbaum RL, Offit K, Öfverholm A, Ong KR, Osorio A, Papi L, Papp J, Pasini B, Pedersen IS, Peixoto A, Peruga N, Peterlongo P, Pohl E, Pradhan N, Prajzendanc K, Prieur F, Pujol P, Radice P, Ramus SJ, Rantala J, Rashid MU, Rhiem K, Robson M, Rodriguez GC, Rogers MT, Rudaitis V, Schmidt AY, Schmutzler RK, Senter L, Shah PD, Sharma P, Side LE, Simard J, Singer CF, Skytte AB, Slavin TP, Snape K, Sobol H, Southey M, Steele L, Steinemann D, Sukiennicki G, Sutter C, Szabo CI, Tan YY, Teixeira MR, Terry MB, Teulé A, Thomas A, Thull DL, Tischkowitz M, Tognazzo S, Toland AE, Topka S, Trainer AH, Tung N, van Asperen C, van der Hout A, van der 
Kolk L, van der Luijt R, van Heetvelde M, Varesco L, VaronMateeva R, Vega A, Villarreal-Garza C, von Wachenfeldt A, Walker L, Wang-Gohrke S, Wappenschmidt B, Weber BHF, Yannoukakos D, Yoon SY, Zanzottera C, Zidan J, Zorn KK, Hutten Selkirk CG, Hulick PJ, Chenevix-Trench G, Spurdle AB, Antoniou AC, Nathanson KL (2018). Mutational spectrum in a worldwide study of 29,700 families with BRCA1 or BRCA2 mutations. Hum Mutat 39(5):593-620

3. Lumish HS, Steinfeld H, Koval C, Russo D, Levinson E, Wynn J, Duong J, Chung WK (2017). Impact of panel gene testing for hereditary breast and ovarian cancer on patients. J Genet Couns 26(5): 1116-1129

4. Caswell-Jin JL et al (2018). Racial/ethnic differences in multiplegene sequencing results for hereditary cancer risk. Genet Med, 20(2):234-239

5. Carbine NE et al (2018). Risk-reducing mastectomy for the prevention of primary breast cancer. Cochrane Database Syst Rev 4: $\mathrm{Cd} 002748$

6. American Cancer Society (ACS), Breast cancer facts and figures 2019-2020. Retrieved from: https://www.cancer.org/content/dam/ cancer-org/research/cancer-facts-and-statistics/breast-cancer-factsand-figures/breast-cancer-facts-and-figures-2019-2020.pdf

7. Trogdon JG, Ekwueme DU, Chamiec-Case L, Guy GP Jr (2016). Breast cancer in young women: health state utility impacts by race/ethnicity. Am J Prev Med 50(2):262-269

8. Shimelis $\mathrm{H}$ et al (2018). Triple-negative breast cancer risk genes identified by multigene hereditary cancer panel testing. J Natl Cancer Inst, 110(8):855-862

9. Jones $\mathrm{T}$ et al (2016). Use of cancer genetics services in AfricanAmerican young breast cancer survivors. Am J Prev Med, 51(4): 427-36

10. Kehl KL, Giordano SH (2016). BRCA1 and BRCA2 testing among young breast cancer survivors. JAMA Oncol 2(5):688-689

11. Kurian AW et al (2018). Uptake, results, and outcomes of germline multiple-gene sequencing after diagnosis of breast cancer. JAMA Oncol, 4(8):1066-1072

12. Kehl KL, Shen C, Litton JK, Arun B, Giordano SH (2016). Rates of BRCA1/2 mutation testing among young survivors of breast cancer. Breast Cancer Res Treat 155(1):165-173

13. Rosenberg, S.M., L.A. Newman, and A.H. Partridge (2015). Breast cancer in young women: Rare disease or public health problem? JAMA Oncol, 1(7):877-8

14. Rosenberg, S.M., et al. (2016). BRCA1 and BRCA2 mutation testing in young women with breast cancer. JAMA Oncol, 2(6):730-6
15. Ruddy KJ, Gelber S, Shin J, Garber JE, Rosenberg R, Przypysny M, Partridge AH (2010). Genetic testing in young women with breast cancer: results from a web-based survey. Ann Oncol 21(4): 741-747

16. Chen Z, Kolor K, Grosse SD, Rodriguez JL, Lynch JA, Green RF, Dotson WD, Bowen MS, Khoury MJ (2018). Trends in utilization and costs of BRCA testing among women aged 18-64 years in the United States, 2003-2014. Genet Med 20(4):428-434

17. Gianmarco, T., Nante, N., Cozzolino, M. (2017). The Angelina Jolie effect - Impact on breast and ovarian cancer prevention A systematic review of effects after the public announcement in May 2013. Health Education. https://doi.org/10.1177/ 0017896917712300

18. Cook-Deegan R, Niehaus A (2014). After Myriad: genetic testing in the wake of recent supreme court decisions about gene patents. Current genetic medicine reports 2(4):223-241

19. Denise G. Jolie's disclosure of preventive mastectomy highlights dilemma. The New York Times. MAY 14. 2013

20. Petrucelli N, Lazebnik N, Huelsman KM, Lazebnik RS (2002). Clinical interpretation and recommendations for patients with a variant of uncertain significance in BRCA1 or BRCA2: a survey of genetic counseling practice. Genet Test 6(2):107-113

21. Ackerman MG, Shapiro PA, Coe A, Trivedi MS, Crew KD (2017). The impact of mental illness on uptake of genetic counseling for hereditary breast cancer and ovarian cancer in a multiethnic cohort of breast cancer patients. Breast J 23(5):519-524

22. Robson M, Im SA, Senkus E, Xu B, Domchek SM, Masuda N, Delaloge S, Li W, Tung N, Armstrong A, Wu W, Goessl C, Runswick S, Conte P (2017). Olaparib for metastatic breast cancer in patients with a germline BRCA mutation. N Engl J Med 377(6): $523-533$

23. McCarthy, A.M., J. Yang, and K. Armstrong (2015). Increasing disparities in breast cancer mortality from 1979 to 2010 for US black women aged 20 to 49 years. Am J Public Health, 2015(0): p. e1-e3.

24. Lumish, HS et al (2017). Impact of panel gene testing for hereditary breast and ovarian cancer on patients. J Genet Couns, 26(5):11161129

25. McKenna A, Shendure J (2018). FlashFry: a fast and flexible tool for large-scale CRISPR target design. BMC Biol 16(1):74

Publisher's Note Springer Nature remains neutral with regard to jurisdictional claims in published maps and institutional affiliations. 